\title{
The Incidence, Aetiology And Treatment of Leiomyoma in Nigeria
}

\author{
Ayeotan $\mathrm{O}^{1}$, Hollands $\mathrm{P}^{2 *}$, Olajuyin $\mathrm{OE}^{3}$, Egbeleke $\mathrm{FA}^{1}$ and 0 yemomi $\mathrm{SS}^{3}$ \\ ${ }^{1}$ Department of Medical Laboratory Science, University College Hospital Ibadan, Nigeria \\ ${ }^{2}$ The Fertility and Gynecology Academy, UK \\ ${ }^{3}$ Department of Medical Laboratory Science, Ladoke Akintola University of Technology Osogbo, Nigeria
}

*Corresponding author: Peter Hollands, The Fertility and Gynecology Academy, UK.

Received Date: October 22, 2020

Published Date: November 25, 2020

\section{Abstract}

Leiomyoma are a significant source of morbidity in reproductive aged woman across the globe causing distressing symptoms and in infertility in some women. There does, however, appear to be an increased incidence of leiomyoma in women of black African ethnicity and especially those women in Nigeria. This review covers the incidence and possibly aetiology and treatment of leiomyoma in Nigeria.

Keywords: Nigeria; Uterine leiomyoma; Genetics; Aetiology; Treatment; Interventions

\section{Introduction}

Uterine leiomyoma, commonly known as uterine fibroids, is a benign tumor often found in women of all races across the world. There is a 3-4-fold likelihood of dominance among African women as opposed to what is seen in other races [1-4]. Leiomyoma occurs mostly in women of reproductive age and have been observed by some workers in $80 \%$ of women in Nigeria within the age range of 25 years and above. Leiomyoma generally begins with a small mass which further grows into a larger mass. There is generally a late presentation of patients at clinics as most leiomyoma is asymptomatic [5,6]. A study by Baird DD, et al. [7] showed a $60 \%$ incidence of leiomyoma among African American women at age 34 with a surge of greater than $80 \%$ when they attain age 50 . This is in contrast to as what was observed in Caucasians who have $40 \%$ incidence at age 35 and $70 \%$ at 50 .

\section{The Aetiology of Leiomyoma}

The aetiology of leiomyoma is currently unknown but many predisposing factors have been proposed such as age, race, nulliparity, early menarche, caffeine and alcohol consumption, positive family history, vitamin D deficiency, hormonal factors, the use of chemical hair products, obesity and genetic factors [810]. The development of leiomyoma is thought to depend upon the female hormones oestrogen and progesterone. Studies have established the presence of oestrogen and progesterone receptors on the surface of leiomyoma along with higher mRNA and protein expression level when compared with the normal myometrium [11-13]. Varying degrees of symptoms have been observed in patients suffering from leiomyoma depending on the size and location of the leiomoyma [14]. The most common symptoms are menorrhagia with secondary anaemia, infertility, pregnancy loss, obstetric complications and pelvic pain [14]. In this review we focus on the genetic predisposition to leiomyoma, the current available therapeutic interventions and the potential of stem cells in the prevention of leiomyoma and optimization of the uterine endometrial environment.

\section{The Genetic Basis of Leiomyoma}

The pathogenesis of leiomyoma is not fully understood. Nevertheless, some insights have been documented such as the observation of Mehine M, et al [15] who linked leiomyoma with 
complex multiple chromosomal rearrangements due to multiple chromosomal breaks and random reassembly. These chromosomal rearrangement result in tissue specific changes observed in leiomyoma which could be explained by the translocation of (High mobility group) HMGA 2 and RAD51B loci and mutation at the COLAA5- COLAA6 HMGA2 gene found in translocation 12:14 which has three DNA binding domains. These domains are responsible for the attachment of its protein to adenine-thymine (AT)-rich regions of DNA. This binding neither promotes nor inhibits the transcription process during myometrial stem cell division but alters the DNA structure to encourage complex formation of transcription regulatory proteins [16]. This single genetic mutation may alter key the signaling pathways such as those involving $\beta$-catenin and TGF- $\beta$. These are major cell proliferation regulators resulting in the inability of the cell to control its survival and senescence [17].

Other chromosomal changes have been directly linked to the pathophysiology of leiomyoma among which includes the observation that $40 \%$ of leiomyoma patients have tumor specific chromosomal mutations $[18,19]$. In familial leiomyoma transferable germline mutations have been observed to result in fumarate deficiency and a gene that could predispose women to leiomyoma has been mapped on chromosome 1q42.3-q43 [20-22]. Despite these observations it is not currently understood how fumarate deficiency promotes the growth of leiomyoma. One possible hypothesis is that mutation in fumarate hydratase in the citric acid cycle could result in leiomyoma development through the citric acid mediated mitochondrial dysfunction causing DNA damage, loss of energy dependent apoptotic function and inhibition of growth factor transcription [23]. In a study conducted by Mäkinen, et al. [24] 18 leimyoma tissues and normal myometrium tissues were subjected to sequencing after which it was shown that $56 \%$ of the leiomyoma tissue (10 of 18) had a mutation in the gene that codes for the mediator complex subunit 12 (MED 12). The MED12 gene (Xq13.1) provides instructions to make a protein, mediator complex subunit 12, which regulates transcription through RNA polymerase II by linking transcription factors which influence whether genes are turned off or on [24]. Mis-sense and in-frame insertion-deletion mutations in the MED12 gene have been confirmed to contribute to the pathogenesis of leiomyoma. The MED12 mutation has been reported to be the most common form of mutation in leiomyomas contributing to about $70 \%$ of all cases [25].

In normal stem cells, the MED12 gene acts as a physiological modifier of $\beta$-catenin; however, when a mutation occurs, this function of the MED12 gene is lost. Moreover, TGF- $\beta$ receptors are expressed in stem cells, which activate mitogenic protein kinase (MAPK) proteins, which regulate cell-cell interactions, renewal, and proliferation of stem cells [26].

In reproductive age women, myometrial smooth-muscle cells undergo cell division and involution under the influence of ovarian hormones or the hormones of pregnancy. A point mutation in MED12 resulting in a chromosomal rearrangement could also result into increased expression of HMGA2, or some other gene defect in a somatic stem cell in the myometrium, may be the initiating factor [27].

It is agreed that leiomyomas are a monoclonal tumor of the myometrium and they have been reported to originate from somatic stem cell transformation influenced by ovarian hormones. This transformation is caused by somatic chromosomal aberration which could be inherited [28] resulting in a predisposition to leiomyoma in families.

The myometrial stem cells are actively dividing cells, responsible for the proliferation of the normal myometrial smoothmuscle cells and cell regeneration [29-31]. The presence of myometrial stem cells was first established in rodents and shortly after in humans in a study carried out by Arango et al., 2005. The presence of multipotent stem cells was observed in the mouse uterus by using flow cytometry and other observations showed that the smooth muscles of the uterus were replaced by adipose tissue upon deletion of $\beta$-catenin. These myometrial stem cells are in the Go phase (senescence stage) of the cell cycle and possesses low expression of oestrogen receptor alpha, progesterone receptor, callponin, and smooth line $[30,32]$. Hypoxia has been implicated in the ability to induce untimely proliferation and differentiation of myometrial stem cells which could lead to leiomyoma formation [30].

Leiomyoma have been investigated using flow cytometry and shown to possess multiple cell types which originate from a single parent cell line that contains multipotent stem cell [33]. Mas et al., [26] used flow cytometry assay to isolate leiomyoma stem cells and found that these stem cells were able to differentiate and selfrenew into fibroid cells when xenotransplantation. These cells were observed to be responsive to signaling by progesterone and estradiol via the WNT/B-catenin pathway. In research recently completed at Harvard University lead by Markus Frank, stem cells that induce melanoma were identified and targeted using antibody that specifically binds the cancer stem cells and significant tumor regression was observed [34].This idea could be applied to leiomyoma, where leiomyoma stem cells could be targeted specifically.

\section{Interventions}

Depending on the age, size and location of leiomyoma, intervention ranges from surgical to non-surgical procedures not limited to myomectomy by either hysteroscopy or laparoscopy, and radiography and ultrasonography to achieve uterine artery embolization (UAE) [35-39]. Drug therapies for the treatment of leiomyoma are not routine but they include the use of Gonadotrophin Releasing Hormone Agonists (GnRHa), Antiprogestins, selective progesterone receptor modulators (SPRMs), aromatase inhibitors, and the use of oral contraceptives. The GnRHa is effective in reducing leiomyoma size up to $40 \%$ in three months and as well a beneficial treatment prior to surgery. However, upon cessation of 
therapy there is regrowth of leiomyoma [40]. Antiprogestins and SPRMs have been documented by Stein et al. [41] and Ouzounian S, et al. [42] to reduce leiomyoma size, regulate bleeding and manage pelvic pressure. Aromatase inhibitor has been documented to significantly improve clinical outcomes of leiomyoma and could also prevent future increase of leiomyoma mass [43-45].

\section{Surgical Intervention in the Treatment of Leiomyoma}

The gold standard for treatment of lieomyoma is surgical intervention. Various surgical procedures are available for the treatment of leiomyoma, these include:

\section{Hysterectomy}

This is the surgical removal of the uterus and any associated leiomyoma. Hysterectomy is especially useful for women who have completed child-bearing. Despite the great advantages of hysterectomy, it is not devoid of risk, morbidities and mortalities associated with surgical procedures [46].

\section{Myomectomy}

This is an option used by women who still desire to have children or who desire to retain their uterus and their fertility [47]. The major disadvantage of myomectomy is that about $50 \%-60 \%$ of patient will develop another leiomyoma within period of 5years [48].

Endometrial ablation: Endometrial ablation offers alternative to surgery in patients with more complicated conditions such as heavy or abnormal uterine bleeding. Most clinical studies on endometrial ablation excluded women with more significant leiomyoma $[47,49]$.

\section{Minimally Invasive Procedures (Uterine Artery Embolization and Uterine Fibroid Embolization)}

Minimally invasive procedures are available in some Countries for the treatment of leiomyoma. They involve the delivery of some particulate emboli through the uterine arteries in order to block nutrient and blood supply to the leiomyoma vessels [50]. Various studies have shown that women who opt for this form of treatment do not need long hospitalization and morbidity is low. Patients resume their work quickly unlike those who underwent myomectomy and hysterectomy [51]. Even though uterine artery embolization is a good and cost-effective treatment option, it also comes with its own complications which include miscarriage, placenta praevia, pre-term labour and post-partum hemorrhage [47]. Limitations of using these techniques to treat patients with large leiomyoma should also be noted [52].

\section{Magnetic Resonance-Guided Focused Ultrasound}

This is a surgical procedure used in the treatment of uterine leiomyoma suitable for pre-menopausal women who no longer desire to give birth. It is a non-invasive procedure which uses the convergence of multiple ultrasound energies on the leiomyoma which leads to destruction of these tissues [53].

\section{Non-Surgical Interventions}

\section{Progestin}

Progestogens are natural, or artificial, hormones which may be capable of intervening in the development of leiomyoma. While the natural hormone progesterone augments epidermal growth factor, which stimulates fibroid growth, it also inhibits insulin-like growth factor-1, which may also additionally inhibit growth [54]. Progestogens as well known to down-regulate both oestrogen and progesterone receptors in leiomyoma. Reduction in the thickness of the endometrium can limit menstrual blood flow in women with leiomyoma [55].

\section{Ulipristal acetate}

Leiomyoma often grow during the reproductive years making one possible intervention to block gonadal steroid action. The full chemical name of ulipristal acetate is $17 \mathrm{a}$-acetoxy-11b-(4-N,Ndimethylaminophenyl)-19norpregna-4,9-diene-3,20 dione or CDB 2914. It binds to human progestin, glucocorticoid and androgen receptors but not oestrogen or mineralocorticoid receptors. It is a selective $\mathrm{P}$ receptor modulator (SPRM) with minimal in vivo anti-glucocorticoid activity as well as anti-proliferative activity on leiomyoma cells and the endometrium [56,57].

Donnez J, et al. [58] studied the actions of ulipristal acetate versus placebo before the surgical treatment of symptomatic leiomyoma. They showed a decrease in leiomyoma size following thirteen weeks of $5 \mathrm{mg}$ and $10 \mathrm{mg}$ of ulipristal acetate of $21.2 \%$ and $12.3 \%$, respectively. The placebo group had a median $3 \%$ increase of leiomyoma size. Patients additionally experienced diminished uterine bleeding following treatment. Levens, et al. [59] showed that a 3-month administration of SPRM CDB-2914 reduced bleeding and leiomyoma size.

\section{Aromatase inhibitors}

Peripheral blood oestrogen concentration in leiomyoma is usually increased [60]. This is because of the secretion of oestrogen from the leiomyoma tissue. This paracrine secretion of oestrogen within leiomyoma may result in increased growth of the leiomyoma [61]. There is increased aromatase activity in leiomyoma related to the oestrogen secretion of the tissue [62].

The inhibition of aromatase (and therefore the reduction of endogenous oestradiol production) using anastrozole which is a selective, third-generation non-steroidal substance which has no effect on cortisol, aldosterone, androgens, progesterone or oestrogen. The use of anastrozole therefore does not induce weight gain, acne and hypertrichosis or alter the lipid profile [63-65].

Song $\mathrm{H}$, et al. [66] have shown that the use of letrozole reduces fibroid volume by $46 \%$ and the use of a gonadotropin releasing hormone agonist by $32 \%$ after 12 weeks of treatment. Nevertheless, they did conclude that these results were not statistically significant. Significantly fewer women reported hot flushes in the letrozole 
group than in the GnRHa group. Letrozole is an aromatase inhibitor which inhibits the conversion of androgen into estrogen.

\section{Gonadotrophin Releasing Hormone (GnRH) Antagonists and Agonists}

GnRH antagonists work by blockage of the hormone mechanism. GnRH agonists are useful pre-operatively to decrease leiomyoma and to limit anaemia related to uterine bleeding $[67,68]$.

The principal advantage of the use of GnRH antagonists is their lack of the preliminary "flare" impact seen with GnRH agonist stimulation and supraphysiological amounts of follicle stimulating hormone, luteinizing hormone, and 0estradiol $[69,70]$.

GnRHa is an artificially produced peptide which is structurally similar to the natural gonadotrophin releasing hormone. It can interact with the GnRH receptors to elicit biological functions. It has a half-life longer than the naturally produced $\mathrm{GnRH}$ and prolonged exposure leads to down regulation effect in hypogonadism which eventually brings about a state of hypoestrogenism by restraining pituitary ovarian function [71]. GnRHa is considered to be effective in the treatment of lieomyoma.

Currently, GnRHa is the solely approved short-term therapy by the FDA for the treatment of lieomyoma [72]. Luporon depot (leuprolide acetate for depot suspension) is a GnRHa approved by the FDA in 1999 which is effective in reducing leiomyoma [72]. GnRHa has side effects which include hypoestrogenism and menopausal symptoms such as vaginitis, tingling, vaginal dryness, breast enlargement and hot flushes [73].

\section{Promising Therapies in Clinical Trial}

\section{Mifepristone}

Mifepristone is an artificially produced steroid which has antiprogesterone and anti-glucocorticoids actions. It is synthesized from precursor norethindrone and it completely inhibits the progesterone receptor [74]. It suppresses the production of prolactin in both the leiomyoma and myometrium even if the patient does not have hyper-prolactinaemia. Some authors have suggested that prolactin levels should be used as a marker for the effectiveness of this therapy [75]. It has been shown that doses of mifepristone (2.5-5.0 $\mathrm{mg} / \mathrm{dL}$ ) was able to reduce the volume of leiomyoma up to approximately 50\% [76].

\section{Asoprisnil}

Asoprisnil is a progesterone receptor modulator which has high binding affinity for the progesterone receptor and mild or moderate affinity for the glucocorticoid receptor. It has low affinity for the androgen receptor and no binding affinity at all for mineralocorticoid receptor [77]. It inhibits the appearance of growth factors TGF- $\beta 3$, IGF-1, EGF and their receptors in a cultured lieomyoma cell without affecting their appearance in myometrial cells [78]. Asoprisnil is known to moderately reduce uterine artery blood flow [79].

\section{Pirfenidone}

A phase II clinical trial of Pirfenidone has been completed. Perfenidone is an effective inhibitor of leiomyoma growth and myometrial cell proliferation in vitro and it is known to reduce the mRNA level of collagen type I and III in a dose- dependent manner [80]. It is a pyridine molecule that shows antifibrotic effect in a variety of animal models [81].

\section{Conclusion}

There is clearly a high incidence of leiomyoma in Nigeria which also seems to extend to African race females living overseas. Leiomyoma is a significant cause of infertility in Nigeria and also has high morbidity for all child-bearing age females. The cause of leiomyoma in Nigerian women could include genetics, environment, pollution, nutrition, age and even life-style. Nigeria is a country with relatively high rates of pollution (domestic and industrial) and this could be significant factor in the development of leiomyoma especially that in Nigeria leiomyoma tend to increase with age which is directly proportional to the exposure of each individual to potential causative agents. There is clearly a genetic component associated with leiomyoma and this needs further research in women of all ages to perhaps develop a more effective and nobinvasive therapeutic approach. It is unlikely that there is a single cause, it is more likely to result from a combination of effects. There are possible indications, from animal studies, that myometrial smooth muscle stem cells may have a role to play in the development of leiomyoma. Much more research is needed here to understand this mechanism and to possibly utilize stem cell technology in the treatment of leiomyoma. There are potential treatments available ranging from invasive surgery to new medications in clinical trial but at present these all have restrictions and drawbacks which makes it difficult to manage patients suffering from leiomyoma. Further research is needed to better understand leiomyoma and to develop new treatments or interventions which may prevent or minimize the development of leiomyoma on a global scale.

\section{Acknowledgement}

None.

\section{Conflict of Interest}

Authors declare no conflict of interest.

\section{References}

1. Al-Hendy A, Salama SA (2006) Ethnic distribution of estrogen receptor- $\alpha$ polymorphism is associated with a higher prevalence of uterine leiomyomas in black Americans. Fertil Steril 86(3): 686-693.

2. Othman E-ER, Al-Hendy A (2008) Molecular genetics and racial disparities of uterine leiomyomas. Best Pract Res Clin Obstet Gynaecol 22(4): 589-601.

3. Al-Hendy A, Laknaur A, Diamond MP, Ismail N, Boyer TG, et al. (2017) Silencing Med12 gene reduces proliferation of human leiomyoma cells mediated via wnt/ $\beta$-catenin signaling pathway. Endocrinology 158(3): 592-603.

4. Vercellini P, Frattaruolo MP (2017) Uterine fibroids: From observational epidemiology to clinical management. BJOG: Int J Obstet Gy 124(10): 1513. 
5. Agboola A (1988) "Tumours of the corpus uteri," Obstetrics and Gynaecology, Agboola A, (edt), , University Services Educational Publishers, Ibadan, Nigeria, $1^{\text {st }}$ (edn), pp. 235-247.

6. Okogbo FO, Ezechi OC, Loto OM, Ezeobi PM (2011) Uterine Leiomyomata in South Western Nigeria: a clinical study of presentations and management outcome. African Health Sciences 11(2): 271-278.

7. Baird DD, Dunson DB (2003) Why is parity protective for uterine fibroids? Epidemiology 14(2): 247-250.

8. De Sa Dias TC, Baby AR, Kaneko TM, Robles Velasco MV (2007) Relaxing/ straightening of Afro-ethnic hair: historical overview. J Cosmet Dermatol 6(1): 2-5.

9. Addo J, Smeeth L, Leon DA (2009) Obesity in urban civil servants in Ghana: Association with pre-adult wealth and adult socio-economic status. Public Health 123(5): 365-370.

10. Paffoni A, Somigliana E, Vigano P, Benaglia L, Cardellicchio L, et al. (2013) Vitamin D status in women with uterine leiomyomas. J Clin Endocrinol Metab 98(8): E1374-E1378.

11. Ukwenya V, Maduemezia N, Afolayan O, Aese O, Thomas W (2015) Prevalence of Uterine fibroid in South-Western Nigeria Population :A sonographic study. Journal of Experimental and Clinical Anatomy 14: 24-29.

12. Benassayag C, Leroy MJ, Rigourd V, Robert B, Honore JC, et al (1999) Estrogen receptors (ER $\alpha / E R \beta)$ in normal and pathological growth of the human myometrium: Pregnancy and leiomyoma. Am J Physiol 276(6): E1112-E1118.

13. Kovács KA, Oszter A, Göcze PM, Péter M, Környei JL, et al. (2001) Comparative analysis of cyclin D1 and oestrogen receptor ( $\alpha$ and $\beta$ ) levels in human leiomyoma and adjacent myometrium. Mol Hum Reprod 7(11): 1085-1091.

14. Donnez J, Dolmans MM (2016) Uterine fibroid management : from the present to the future. Hum Reprod Update 22(6): 665-686.

15. Mehine M, Makinen N, Heinonen HR, Aaltonen LA, Vahteristo P, et al. (2014) Genomics of Uterine Leiomyomas: insights from highthroughput sequencing. Fertil Steril 102(3): 621-629.

16. Hodge JC, Cuenco KT, Huyck KL, Somasundaram P, Panhuysen CI, et al. (2009) Uterine leiomyomata and decreased height: a common HMGA2 predisposition allele. Human genetics 125(3): 257-263.

17. Baranov VS, Osinovskaya NS, Yarmolinskaya MI (2019) Pathogenomics of Uterine Fibroids Development. Int J Mol Sci 20(24): 6151

18. Nilbert M, Heim S, Mandahl N, Floderus UM, Willen H, et al. (1988) Ring formation and structural rearrangements of chromosome 1 as secondary changes in uterine leiomyomas with $\mathrm{t}(12 ; 14)(\mathrm{q} 14-15 ; \mathrm{q} 23-24)$. Cancer Genet Cytogenet 36(2): 183-190.

19. Rein MS, Friedman AJ, Barbieri RL, Pavelka K, Fletcher JA, et al. (1991) Cytogenetic abnormalities in uterine leiomyomata. Obstet Gynecol 77(6): 923-926.

20. Alam NA, Bevan S, Churchman M, Barclay E, Barkeret K, et al. (2001) Localization of a gene (MCUL1) for multiple cutaneous leiomyomata and uterine fibroids to chromosome 1q42.3-q43. Am J Hum Genet 68(5): 1264-1269

21. Kiuru M, Launonen V, Hietala M, Aittomäki K, Vierimaa O, et al. (2001) Familial cutaneous leiomyomatosis is a two-hit condition associated with renal cell cancer of characteristic histopathology. Am J Pathol 159(3): 825-829.

22. Launonen V, Vierimaa O, Kiuru M, Isola J, Roth S, et al. (2001) Inherited susceptibility to uterine leiomyomas and renal cell cancer. Proc Natl Acad Sci 98(6): 3387-3392.

23. Eng C, Kiuru M, Fernandez MJ, Aaltonen LA (2003) A role for mitochondrial enzymes in inherited neoplasia and beyond. Nat Rev Cancer 3(3): 193-202.

24. Mäkinen N, Mehine M, Tolvanen J, Kaasinen E, Li Y, et al. (2011) MED12, the mediator complex subunit 12 gene, is mutated at high frequency in uterine leiomyomas. Science 334(6053): 252-255.
25. Lee M, Cheon K, Chae B, Hwang H, Kim HK, et al. (2018) Analysis of MED12 mutation in multiple uterine leiomyomas in South Korean patients. Int J Med Sci 15(2): 124-128.

26. Mas A, Cervello I, Gil-Sanchis C, Simón C (2014) Current understanding of somatic stem cells in leiomyoma formation. Fertil steril 102(3): 613620.

27. Bulun SE (2013) Uterine fibroids. N Engl J Med 369(14): 1344-1355.

28. Linder D, Gartler SM (1965) Glucose-6-phosphate dehydrogenase mosaicism: utilization as a cell marker in the study of leiomyomas. Science 150(3692): 67-69.

29. Arango NA, Szotek PP, Manganaro TF, Oliva E, Donahoe PK, et al. (2005) Conditional deletion of $\beta$-catenin in the mesenchyme of the developing mouse uterus results in a switch to adipogenesis in the myometrium. Dev Biol 288(1): 276-283.

30. Ono M, Maruyama T, Masuda H, Kajitani T, Nagashima T, et al. (2007) Side population in human uterine myometrium displays phenotypic and functional characteristics of myometrial stem cells. Proc Natl Acad Sci U S A 104(47): 18700-18705.

31. Szotek PP, Chang HL, Zhang L, Preffer, F, Dombkowski D, et al. (2007) Adult mouse myometrial label-retaining cells divide in response to gonadotropin stimulation. Stem Cells 25(5): 1317-1325.

32. Ono M, Yin P, Navarro A, Moravek MB, Coon JS, et al. (2013) Paracrine activation of WNT/ $\beta$-catenin pathway in uterine leiomyoma stem cells promotes tumor growth. Proc Natl Acad Sci USA110(42): 17053-17058.

33. Holdsworth-Carson SJ, Zaitseva M, Vollenhoven BJ, Rogers PA (2014) Clonality of smooth muscle and fibroblast cell populations isolated from human fibroid and myometrial tissues. Mol Hum Reprod 20(3): 250-259.

34. Harvard stem cell institute (2020) Stem cells and cancer

35. Donnez J, Jadoul P (2002) What are the implications of myomas on fertility? A need for a debate? Hum Reprod 17(6): 1424-1430.

36. Practice Committee of American Society for Reproductive Medicine in collaboration with Society of Reproductive Surgeons (2008) Myomas and reproductive function. Fertil Steril 90(5 Suppl): S125-S130.

37. Lumsden MA, Hamoodi I, Gupta J, Hickey M (2015) Fibroids: diagnosis and management. British Medical Journal 351: h4887.

38. Stewart EA (2015) Clinical practice. Uterine fibroids. N Engl J Med 372(17): 1646-1655.

39. Zupi E, Centini G, Sabbioni L, Lazzeri L, Argay IM, et al. (2015) Nonsurgical alternatives for uterine fibroids. Best Pract Res Clin Obstet Gynaecol 34: 122-131.

40. Weiss SW, Goldblum JR (2001) Enzinger and Weiss's Soft Tissue Tumors. $4^{\text {th }}(\mathrm{edn})$, Philadelphia: Mosby-Harcourt pp.727-748.

41. Stein K, Ascher-Walsh CA (2009) A comprehensive approach to the treatment of uterine leiomyomata. Mt Sinai J Med 76(6): 546-556.

42. Ouzounian S, Bouchard P, Chabbert-Buffet N (2008) Effects of antiprogestins on the uterus. Womens Health 4(3): 269-280.

43. Khuraseva AB, Konoplya AA, Odiase BE, Brimpong BB, Acquah A (2019) Etiological reasons, screening, and simple prophylactic measures of uterine fibroid in women of African descent. MOJ Women's Health 8(3): 222-224.

44. Varelas FK, Papanicolaou AN, Vavatsi-Christaki N, Makedos GA Vlassis GD (2007) The effect of anastrazole on symptomatic uterine leiomyomata. Obstet Gynecol 110(3) : 643-649.

45. Attilakos G, Fox R (2005) Regression of tamoxifen-stimulated massive uterine fibroid after conversion to anastrozole. J Obstet Gynaecol 25(6): 609-610.

46. Elizabeth A, Stewart M (2010) Overview of treatment of uterine leiomyomas (fibroids). Robert L, Barbieri M (edt).

47. Sabry M, Al-Hendy A (2012) Medical Treatment of Uterine Leiomyoma. Reprod Sci 19(4): 339-353. 
48. Hanafi M (2005) Predictors of leiomyoma recurrence after myomectomy. Obstet Gynecol 105(4): 877-881.

49. Arena S, Zupi E (2011) Heavy menstrual bleeding: considering the most effective treatment option. Womens Health 7(2): 143-146.

50. Goodwi SC, Spies JB (2009) Uterine fibroid embolization. N Engl J Med 361(7): 690-697.

51. Freed MM, Spies JB (2010) Uterine artery embolization for fibroids: a review of current outcomes. Semin Reprod Med 28(3): 235-241.

52. Levy BS (2008) Modern management of uterine fibroids. Acta Obstet Gynecol Scand 87(8): 812-823.

53. Stewart EA, Gedroyc WM, Tempany CM, Quade BJ, Inbar Y, et al. (2003) Focused ultrasound treatment of uterine fibroid tumors: safety and feasibility of a noninvasive thermoablative technique. Am J Obstet Gynecol 189(1): 48-54.

54. Maruo T, Ohara N, Yoshida S, Nakabayashi K, Sasaki H, et al. (2010) Translational research with progesterone receptor modulator motivated by the use of levonorgestrel-releasing intrauterine system. Contraception 82(5): 435-441.

55. Sayed GH, Zakherah MS, El-Nashar SA, Shaaban MM (2010) A randomized clinical trial of a levonorgestrel-releasing intrauterine system and a lowdose combined oral contraceptive for fibroid-related menorrhagia. Int J Gynaecol Obstet 112(2): 126-130.

56. Attardi BJ, Burgenson J, Hild SA, Reel JR (2004) In vitro antiprogestational/ antiglucocorticoid activity and progestin and glucocorticoid receptor binding of the putative metabolites and synthetic derivatives of CDB2914, CDB-4124, and mifepristone. J Steroid Biochem Mol Biol 88(3): 277-288.

57. Chabbert-Buffet N, Pintiaux-Kairis A, Bouchard P VA2914 Study Group (2007) Effects of the progesterone receptor modulator VA2914 in a continuous low dose on the hypothalamic-pituitary-ovarian axis and endometrium in normal women: a prospective, randomized, placebocontrolled trial. The Journal of Clinical Endocrinology and Metabolism 92(9): 3582-3589.

58. Donnez J, Tatarchuk TF, Bouchard P, Puscasiu L, Zakharenko NF, et al. (2012) Ulipristal acetate versus placebo for fibroid treatment before surgery. The New England Journal of Medicine 366(5): 409-420.

59. Levens ED, Potlog-Nahari C, Armstrong AY, Wesley R, Premkumar A, et al. (2008) CDB-2914 for uterine leiomyomata treatment: a randomized controlled trial. Obstet Gynecol 111(5): 1129-1136.

60. Pasqualini JR, Cornier E, Grenier J, Vella C, Schatz B, et al. (1995) Effect of Decapeptyl, an agonist analog of gonadotropin-releasing hormone on estrogens, estrogen sulfates and progesterone receptors in leiomyoma and myometrium. Fertil Steril 53(6): 10012-10017.

61. Sumitani H, Shozu M, Segawa T, Murakami K, Yang H, et al. (2000) In situ estrogen sythesized by aromatase P450 in uterine leiomyoma cells promotes cell growth probably via an autocrine/intracrine mechanism. Endocrinology 141(10): 3852-3860.

62. Andersen J, DyReys VM, Barbieri RL, Cochman DM, Miksicek RJ (1995) Leiomyoma primary cultures have elevated transcriptional response to estrogen compared with autologous myometrial cultures. J Soc Gynecol Investig 2(3): 542-551.

63. Bajetta E, Zilembo N, Noberasco C, Matinetti A, Mariani L, et al. (1997) The minimal effective exemestane dose for endocrine activity in advanced breast cancer. European Journal of Cancer 33(4): 587-591.

64. Michaud LB, Buzdar AU (1999) Risks and benefits of aromatase inhibitors in postmenopausal breast cancer. Drug Saf 21(4): 297-309.

65. Buzdar A, Douma J, Davidson N, Elledge, R, Morgan, et al. (2001) Phase III, multicentre, double-blind, randomized study of letrozole, an aromatase inhibitor, for advanced breast cancer versus megestrol acetate. J Clin Oncol 19(14): 3357-3566

66. Song H, Lu D, Navaratnam K, Shi G (2013) Aromatase inhibitors for uterine fibroids. Cochrane Database of Systematic Reviews 10: CD009505.

67. Friedman AJ, Hoffman DI, Comite F, Browneller RW, Miller JD (1991) Treatment of leiomyomata uteri with leuprolide acetate depot: a doubleblind, placebo-controlled, multicenter study. The Leuprolide Study Group. Obstet Gynecol 77(5): 720-725.

68. Vercellini P, Crosignani PG, Mangioni C, Imparato E, Ferrari A, et al. (1998) Treatment with a gonadotrophin releasing hormone agonist before hysterectomy for leiomyomas: results of a multicentre, randomized controlled trial. Br J Obstet Gynaecol 105(11): 1148-1154.

69. Reissmann T, Diedrich K, Comaru-Schally AM, Schally AV (1994) Introduction of LHRH-antagonists into the treatment of gynaecological disorders. Hum Reprod 9(5): 769.

70. Britten JL, Malik M, Levy G, Mendoza M, Catherino WH (2012) Gonadotropin-releasing hormone (GnRH) agonist leuprolide acetate and GnRH antagonist cetrorelix acetate directly inhibit leiomyoma extracellular matrix production. Fertility and Sterility 98(5): 1299-1307.

71. Broekmans FJ, Hompes PG, Heitbrink MA, Netelenbos CC, Roos JC, et al. (1996) Two-step gonadotropin- releasing hormone agonist treatment of uterine leiomyomas: standard-dose therapy followed by reduced-dose therapy. Am J Obstet Gynecol 175(5): 1208-1216.

72. Md Soriful I, Olga P, Stefano R, Giannubilo P, Toti A, et al. (2013) Uterine Leiomyoma: Available Medical Treatments and New Possible Therapeutic Options. J Clin Endocrinol Metab 98(3): 921-934.

73. Stovall TG, Muneyyirci-Delale O, Summitt RL, Scialli AR (1995) GnRH agonist and iron versus placebo and iron in the anemic patient before surgery for leiomyomas: a randomized controlled trial. Leuprolide Acetate Study Group. Obstet Gynecol 86(1): 65-71.

74. Cadepond F, Ulmann A, Baulieu EE (1997) RU486 (mifepristone): mechanisms of action and clinical uses. Annu Rev Med 48: 129-156.

75. Stewart EA, Austin DJ, Jain P, Penglase MD, Nowak RA (1996) RU486 suppresses prolactin production in explant cultures of leiomyoma and myometrium. Fertil Steril 65(6): 1119-1124.

76. Eisinger SH, Fiscella J, Bonfiglio T, Meldrum S, Fiscella K (2009) Open label study of ultra low-dose mifepristone for the treatment of uterine leiomyomata. Eur J Obstet Gynecol Reprod Biol 146(2): 215-218.

77. DeManno D, Elger W, Garg R, Lee R, Schneider B, et al. (2003) Asoprisnil (J867): a selective progesterone receptor modulator for gynecological therapy. Steroids 68(10-13): 1019-1032.

78. Wang J, Ohara N, Wang Z, Chen W, Morikawa A, et al. (2006) A novel selective progesterone receptor modulator asoprisnil (J867) downregulates the expression of EGF, IGF-I, TGFb3 and their receptors in cultured uterine leiomyoma cells. Hum Reprod 21(7): 1869-1877.

79. Wilkens J, Chwalisz K, Han C, Walker J, Cameron IT, et al. (2008) Effects of the selective progesterone receptor modulator asoprisnil on uterine artery blood flow, ovarian activity, and clinical symptoms in patients with uterine leiomyomata scheduled for hysterectomy. J Clin Endocrinol Metab 93(12): 4664-4671.

80. Lee BS, Margolin SB, Nowak RA (1998) Pirfenidone: a novel pharmacological agent that inhibits leiomyoma cell proliferation and collagen production. J Clin Endocrinol Metab 83(1): 219-223.

81. Iyer SN, Wild JS, Schiedt MJ, Hyde DM, Margolin SB, et al. (1995) Dietary intake of pirfenidone ameliorates bleomycin-induced lung fibrosis in hamsters. J Lab Clin Med 125(6): 779-785 